\title{
Defining Civilization Up and Down
}

\section{Carol Iannone}

I've been thinking lately of how many people I know who fled tyranny and found refuge in the United States. Here are just a few: a Cuban friend came with virtually nothing at age seventeen a few years after Castro took power. Life in Iran deteriorated for Jews with the overthrow of the shah and the ascendence of the mullahs, and an Iranian acquaintance eventually found a way to bring her family here. My own father had his fingers broken by Mussolini's fascist police and reluctantly sailed to America lest worse things befall him. He had nightmares for many years afterward, but he was able to make a new start here.

I grew up during the Cold War, thinking America was a bastion of freedom, a beacon to the world, exceptional among nations. While news from the Soviet Union emerged of innocent citizens being arrested, interrogated, tortured, imprisoned, and sent to Siberia, (this was before Solzhenitsyn named it the "gulag"), my mother used to say, in America you won't hear the knock on the door in the middle of the night. Yet American citizens are hearing that very knock, and what it entails. Many others of us are feeling the weight of coercive government actions and the erosion of basic freedoms once taken as birthright, and our sleep is troubled.

Protesting citizens are being termed enemies and domestic terrorists by an administration that is proving alarmingly authoritarian in a way that a short time ago would have seemed unrecognizable and outrageous. Mandating citizens to take vaccinations, for example, or lose their jobs, thus trespassing on the right to bodily integrity, while, by the way, illegal aliens from multiple countries stream unimpeded across the southern border to be settled surreptitiously in various localities without so much as a covid test.

The countercultural left that started in the 1960s in academia and beyond is now swollen to an ever expanding progressivism. Garden variety political correctness, bad enough in its time, has been surpassed by cancel culture and

Carol lannone is editor-at-large of Academic Questions, 420 Madison Avenue, 7th Floor, New York, NY 10017; iannone@nas.org. 
woke-ism, topped off with belligerent anti-white racism, destructive of civilization altogether (Antifa, defund the police) and of our cultural legacy in particular (radicalized curricula, devaluation of great works, elevation of dreadful diversity stuff).

All these things and more have been developing over decades, but they have accelerated in the past few years, and are now going at the gallop. It's become just routine to rattle off the institutions controlled by the progressive left that might once have been part of the unofficial checks and balances countering the accumulation of government power-lower ed, higher ed, Hollywood, the media, the tech sector, corporate America, and even the military.

The official checks and balances have also not been working as they should. Former U.S. Senator Rick Santorum lamented in a recent interview that he never would have expected Congress to be so little protective of its own power as to surrender much of it to the courts and the executive.

While the speech of some is restricted, that of others has grown coarse, loud, and irrational. With impunity black professors speak of killing white people and Black Lives Matter encourages mob violence and looting. No one even invokes the double standard anymore, not that it was ever very effective, but it did at least rhetorically recall one-time expectations of proper behavior. Black activists and their supporters are given the widest possible berth in endorsing mayhem and we're expected simply to accept it as some aspect of retributive or restorative justice.

How has this happened? We've been maintaining a credible conservative opposition to the counterculture of the Sixties and Seventies, at least since the 1980s and the rise of the great Ronald Reagan, during whose presidency the National Association of Scholars took form, and Allan Bloom's The Closing of the American Mind (1987) crystallized for a general audience what was going wrong in liberal arts education. Why has conservatism not been more successful?

There are several factors to consider. The first, perhaps hard to believe at this point, lies in its early success.

Neoconservative thinking was powerful in inspiring, explaining, and supporting the change of direction that the Reagan presidency signaled: a strong stand against Communism, freer markets, less regulation, turning away from the Great Society and government solutions toward more emphasis on individual responsibility, both in curbing the excesses of the welfare state and in fighting crime. 
Not long after Reagan left office, the Soviet Union fell, something that had once appeared utterly impossible. One day, it seemed, we were facing the endlessly "long twilight struggle," and one evening the Berlin Wall was being dismantled. Not too long after that, a Democratic administration saw bipartisan passage of welfare reform. Further, American cities had for years been helplessly tolerating crime, danger, and shabby streets-New York Senator Daniel Patrick Moynihan called it "defining deviancy down" (car owners, for example, tried to forestall the inevitable break-ins by posting signs in the windows saying “no radio")-but under smart new policies, crime was curbed and New York City and other locales began to sparkle.

All of which leads to the second factor, what the Greeks called hubris and the Bible calls idolatry. We were it-liberal democracy was the end of history, the last stop in human development, the best of all possible worlds. The effects of the mass Third World immigration precipitated by the 1965 Immigration and Nationality Act had become evident before the turn of the century. It was happening without the more purposeful assimilation of previous waves of immigration, but instead under the aegis of multiculturalism and diversity. The response was to proclaim the United States as built solely on ideas, not culturefreedom, equality, and natural rights accessible to all mankind, regardless of particularities of origin. Any concerns about disunity and divisiveness and the need to lower numbers to facilitate greater assimilation was contemptible.

As Daniel McCarthy describes it:

Patriotism and religion were indispensable in the West's confrontation with communism, but they were among the losers of the Cold War. The conservative parties and civil institutions that might be expected to champion a nation or a faith had, by the late 1980s, allied themselves so closely with the ideology of liberal democracy that they had become culturally uprooted. Right-leaning magazines and think tanks, American ones especially, discarded the idea of specific national interests in favor of universal rights and the logic of worldwide markets. All the world wanted to be America, the theory went, and American Americans were no better than non-American Americans. On the contrary, the American in spirit was always to be preferred to the merely legal citizen. 
By the time that history had reasserted itself on September 11, 2001, globalism had so far advanced that the response to the attacks was not to shore up our ruins and strengthen our own culture but to bring liberal democracy to the world. As George W. Bush proclaimed in his Second Inaugural Address in 2005, "the call of freedom comes to every mind and every soul," and "this untamed fire of freedom will reach the darkest corners of our world.”

Much of this was inspired by the openness and generosity of the American spirit, but a snarly, angry side also emerged, with the willingness to cry racism at anyone who disagreed even a sliver with the ecstatic celebration of what the ebullient Ben Wattenberg called the universal nation, making free discussion of the enormous changes happening in the country's character unconscionably difficult and barbed. The same thinking applied to the democracy project; only a bigot could imagine some peoples might not be ready for self-government at the present time.

It may not have been the intention, but all this had the effect of downgrading the importance of the cultural legacy that was the charge of the educational establishment, particularly higher education, to pass on, and that at least in part had led to the formation of citizens who could understand the underlying virtues of representative democracy (rationality, tolerance, debate, fairness, individualism), and develop the ability to participate in it.

Americans were divided into groups, largely color coded, and equality was turned into "equity," group proportionality of outcome aided by aggressive affirmative action and the lowering and even obliteration of liberal standards and their replacement with restrictions on speech and scholarship. Diversity not only dictated the outward form of education in group representation of faculty, administration, and student body, but increasingly the content of the curriculum as well, supposedly aimed at instilling readiness to participate in the new global order.

The progressive left was only too happy to join both in the ecstasy of transformation aided by the new immigration, and in the vilification of anyone who expressed concern as, naturally, a bigot, a racist, someone who supposedly couldn't abide "the browning of America," as if that was all that was happening, as if that wasn't being used to turn America into a balkanized, neo-Marxist state of group rights, with white oppressors and non-white victims. And that may be another factor in the failure of contemporary conservatism, a hidden 
serpent-neoconservatism-had accepted more of the progressive vision than had been understood.

In good communist fashion, any objections to the new diversity regime were due, of course, to racism, now escalated to "systemic racism," "white privilege," and the crowning indictment, "white supremacy," fabricated, inflammatory labels emanating even from the present White House. White supremacy, especially, by which is meant that white people have the audacity to continue as the majority, is clearly meant to evoke apartheid South Africa, suggesting the aim is to use immigration to change U.S. demographics more closely to resemble those of South Africa, where the destiny as depicted in Nobel Laureate J.M. Coetzee's disturbing novel Disgrace (1999) lies in a non-white majority gaining ascendancy and subjugating, degrading, and humiliating a despised white minority. Long ago someone told me that the animating principle of the left is not justice, but revenge.

What about the other strains that comprised conservative thinking? Libertarianism generally opposed political correctness, but also cheered open borders, and, with no transcendent vision, contributed to the coarsening of the culture in permissiveness toward pornography, profanity, obscenity, and vulgarity under the guise of freedom.

For its part, what came to be called paleo conservatism did contain more of a conception of an organic culture, often made pointed criticisms of the fragility of the "ideas" without a cultural infrastructure to support them, and was astute in seeing the various surrenders official conservatism makes to progressive provocations. But there were lapses, to which Michael Anton has called attention. Some seem still to be fighting the Civil War, in a manner of speaking, in despising Lincoln and defending the Secession. This is not helpful and works against the unity needed to fight today's demonic neo-Marxism. And paleo conservatism tends retroactively to slight united America's heroic achievement in winning the two twentieth century world wars against fascism and imperialism. It fosters retroactive self-satisfied condemnation of Allied tactics and thus even manages praise for the despicable work of Howard Zinn.

There were sober voices of warning, if sometimes indirect. Much of the work of Gertrude Himmelfarb, herself a neoconservative, was precisely about manners, morals, ethics, and the importance of the underlying culture shaping individual behavior and civic life. Libertarian guru Milton Friedman emphatically proclaimed the dangers of open borders in a welfare state. And Jeanne 
Kirkpatrick was reportedly offended to see that her seminal analysis of how the U.S. should engage with authoritarian regimes, "Dictatorships and Double Standards," was disregarded when the Bush administration planned the invasions of Afghanistan and Iraq and the overthrow of Saddam. More directly addressing the need for revised thinking about immigration was Lawrence Auster's brilliant and superbly written long essay, "The Path to National Suicide."

The good news is that more on the right are recognizing the mistakes of the past. A movement toward "national conservatism" has formed following the publication of The Virtue of Nationalism by Yoram Hazony in 2018. Parents and teachers are vehemently objecting to the critical race theory-based propaganda infecting lower education. Understanding the importance of an underlying cultural infrastructure to sustain representative self-government and the educational excellence needed in turn to support it, informs the work of many right of center thinkers, such as Amy Wax, Heather Mac Donald, Lawrence Mead, and Peter Wood. Many of the reports and projects of the NAS are devoted to the cultivation of cultural and intellectual foundations, from the scientific method to civics education. Charles Kesler now questions the assumption that drove the Iraq and Afghanistan incursions, perhaps based on a misunderstanding of the work of political philosopher Leo Strauss. Referring to Bush's second inaugural, Kesler suggests that the natural right to be free is potential, but not automatic. It "needs to be made actual, needs to be awakened by practice and habit."

Also, something long hoped for-the Damascene moments when liberals recognize what has become of their political creed-is happening. And parts of Europe are also waking up. Eric Zemmour, journalist and candidate in the next French presidential election, calls on Muslim migrants to France to assimilate, to "appropriate the history, the customs, the way of life, the tastes, the literature" of France, its "language" and "landscape."

And we are being blessed by a new birth of energy and freedom, evident in numerous healthy initiatives, developments, movements, organizations, websites, podcasts, newsletters, campaigns, and, of course, Academic Questions.

Keith Whitaker introduces the symposium in this issue, "Liberal Education and Politics," which addresses how liberal education can respond to the menacing political pressures of today, in which, for example, “equality” has become coercive egalitarianism demanding the heads of anyone who even indirectly suggests, along with Aristotle, that men generally are more rational than 
women. David Bolotin, tutor emeritus at St. John's College in Santa Fe surprisingly reveals that in his thirty years of experience in the Great Books program there, such questions were never even discussed in class. Stephen Eide, Helen Andrews, David Acevedo, and Alex Priou respond and Bolotin rejoins.

In a way, most of the articles in this issue also address that problem, how do we sustain informed intellectual discourse in the face of aggressive irrationality and hatred of truth.

-Alexander Riley, "Of College and Community in the Wake of George Floyd," discusses what happened in the chilling final moments at Jonestown, before the collective suicide of over 900 human beings at the command of their cult master, and sees similarities to conformist thinking on his own campus.

-In “Modern Civilization, and the Fate of Anthropology," Geoffrey Clarfield recounts how he came to understand "the consensus of my professors who preached that people are the same everywhere but differ only in culture, that all cultures are somehow equally valid, and that by implication, they are all equally complex.” For the counter view, Clarfield highlights the work of British anthropologist Christopher Hallpike, who sees a profound difference between primitive and modern peoples. Hallpike reflects on his career in an interview with Clarfield included in the article.

-Academic racism "is not Bull Connor's racism," says author William L. Howard. “It's worse.” It's “an intellectualized and race-based ideology of hatred,” he explains in “Academic Racism.”

-For Robert Leroux, "Woke ideology and the University,” woke ideology is not just censorship but "intellectual terrorism" that can break into physical violence.

- Christopher C. Hull answers the question in his title, "Does Diversity Hiring Decrease Ideological Diversity?" with eye opening data on how more women and minorities on the faculty is producing more leftism. Surprise?

-In “Back to Race, Racism, and Inconvenient Truths,” J. Daryl Charles combats the false premises of the UN "Report of the United Nations High Commissioner for Human Rights," which led to a resolution protecting "the human rights and fundamental freedoms of Africans and people of African descent against” worldwide "systemic," "structural," and "institutional” racism.

-In “The Art of Teaching and the End of Wokeness," Adam Ellwanger suggests combatting new-fangled radicalism by being an old-fashioned teacher. 
- Given recent examples of professors being forbidden to teach undergraduates or first year students for some thought crime, Mark Mercer offers a few theoretical but highly relevant guidelines regarding the proper use of faculty discipline in “The Use and Abuse of University Discipline.”

-Fred Baumann renders a thoughtful comparison of two newer woke-conscious entries in the campus fiction genre, in “That's Hilarious: The Campus as Comedy."

-We will have a longer review of Peter Wood's new book, Wrath: America Enraged, in an upcoming issue. For now, Wight Martindale Jr. savors it in a Short Take., “A Brief Review of Wrath: America Enraged.” In a second Short Take, “Equity Begins at the Top: A Modest Proposal,” Michael Wesley Suman modestly proposes that progressive professors practice what they preach and put their money where their mouth is.

- Steve Balch remembers Donald Kagan, Earnest B. Hook answers a challenge from Henry H. Bauer, and we finish with a stirring and evocative poetry section. 